\title{
Development of Exogenous Insulin Antibody Syndrome in a Patient with Newly Diagnosed Type 1 Diabetes Successfully Treated with Oral Immunosuppressive Monotherapy
}

\author{
Terri Jerkins · David S. H. Bell (D)
}

Received: June 2, 2021 / Accepted: July 23, 2021 / Published online: August 17, 2021

(c) The Author(s) 2021

\begin{abstract}
Exogenous insulin antibody syndrome (EIAS), which rarely occurs in the patient with type 1 diabetes, results in antibody-induced insulin resistance, hyperglycemia, ketosis, ketoacidosis, and hypoglycemia when insulin is released from the saturated insulin antibodies. Recommended treatment regimens include glucocorticoids, immunosuppressants, and plasmapheresis. In the patient with type 1 diabetes, glucocorticoids may by inducing and/or worsening ketoacidosis be contraindicated. With immunosuppressants, various anecdotal treatment regimens have been reported. Currently the most commonly recommended regimen is intravenous immunosuppressive therapy in combination with oral immunosuppressants. Herein we describe a patient in whom oral immunosuppressant monotherapy with mycophenolate resulted in the cure of EIAS, thus avoiding the expense associated with intravenous immunosuppressant therapy and/ or hospitalization for plasmapheresis.
\end{abstract}

\section{T. Jerkins}

Midstate Endocrine Associates, Nashville, TN, USA

e-mail: sugars4jerkins@lipscomb.edu

\section{S. H. Bell (ه)}

Southside Endocrinology, 1900 Crestwood Blvd, \#201, Irondale, AL 35210, USA

e-mail: dshbell@yahoo.com
Keywords: Type 1 diabetes; Insulin antibodies; Oral immunosuppressants; Exogenous insulin antibody syndrome

\section{Key Summary Points}

Insulin antibody syndrome results in insulin resistance, hyperglycemia and later hypoglycemia.

Therapies for insulin antibody syndrome are anecdotal and include plasmapheresis, immunosuppression and glucocorticoids.

The most common current recommendation is combined intravenous and oral immunosuppressants.

In this case we show the efficacy of the more convenient and economic oral immunosuppressant monotherapy.

\section{INTRODUCTION}

Insulin resistance is defined as the need to use 200 or more units of insulin a day or more than 2 units of insulin per kilogram of body weight. Insulin resistance caused by the generation of insulin antibodies has been name exogenous 
insulin antibody syndrome (EIAS) [1]. First isolated in 1956, insulin antibodies were shown to be present in $98 \%$ of patients who utilized insulin when only insulins derived from animal sources were available [2]. Since that time, with the use of more purified insulins the incidence has dropped significantly but EIAS still occurs with the use of both human and analogue insulins [3, 4]. Some analogues have shown decreased antibody formation but there is no consistent recommendation for changes in insulin formulation to decrease insulin antibodies $[5,6]$.

Severe insulin resistance due to exogenous insulin antibodies is extremely rare and is estimated to occur in less than $0.17 \%$ of patients with diabetes. Insulin antibody levels have not been shown to correlate with glycemic control. However, the EIAS causes extreme insulin resistance leading to post-prandial hyperglycemic and ketosis and severe hypoglycemia due to release of insulin from the insulin antibody complex. The majority of case reports are in patients with type 2 diabetes, and EIAS is very uncommon in type 1 diabetes where it has been associated with diabetic ketoacidosis (DKA).

Similar presentations have occurred in the presence of endogenous insulin antibodies (Hirata syndrome) and in the insulin receptor antibody syndrome. Treatment of all of these syndromes has focused on elimination of hypoglycemia because of the increased mortality associated with hypoglycemia.

In 2010, the US National Institutes of Health issued guidelines for the treatment of insulin receptor antibodies causing insulin resistance. Initial therapy is glucocorticoids; if glucocorticoids are not successful, treatment with oral or intravenous immunosuppression and/or plasmapheresis is undertaken [7]. All of these treatments have been tried in EIAS with varying results. However, treatment has not been instituted until the syndrome has been present for at least 5 months. We present a patient who was treated within 2 weeks of the diagnosis of type 1 diabetes due to rapidly accelerating insulin requirements and recurrent DKA despite very high doses of insulin and no hypoglycemia.

Written informed consent was obtained from the patient.

\section{CASE PRESENTATION}

A 51-year-old woman was in her usual state of good health until 10 days prior to hospital admission when she suddenly developed polyuria, polydipsia, and weight loss accompanied by a serum glucose of $594 \mathrm{mg} / \mathrm{dl}$, a metabolic acidosis, and elevated serum beta-hydroxybutyrate. She had no history of glucose intolerance or gestational diabetes though her family history was positive for type 2 diabetes in her father as well as autoimmune thyroid disease in her sister and a niece. She was easily treated with a low dose intravenous insulin DKA protocol and quickly transitioned to a basal bolus subcutaneous insulin regimen utilizing detemir and aspart insulins. At the onset, HbA1c was $11.8 \%$. GAD-65 antibodies were positive at $3184.1 \mathrm{U} / \mathrm{ml}$, antipancreatic islet cell antibodies were $1: 256$, and other than a positive antiparietal antibody a screen for other autoimmune endocrinopathies was negative. She was discharged on detemir 18 units at bedtime and aspart 8 units with each meal (0.58 units $/ \mathrm{kg}$ ).

She was seen as an outpatient 4 days after discharge and was noted to have had a rapid increase in glucose levels. Insulin antibodies were measured and found to be $13 \mu \mathrm{U} / \mathrm{ml}$ (normal $<5 \mu \mathrm{U} / \mathrm{ml}$ ). Over the next week her insulin was rapidly increased. However, even rapid increases in insulin doses (detemir 80 units daily and multiple boluses of 60 units aspart up to five times daily) did not lower her blood sugar levels so that she soon developed ketoacidosis in spite of utilizing 225 units of insulin per day. On readmission to hospital, she required 50\% more intravenous insulin than on the previous admission to achieve glycemic control. Transitioning to subcutaneous human $\mathrm{NPH}$ and regular insulin at more than 400 units of insulin per day failed to control her hyperglycemia and continuous subcutaneous insulin infusion (CSII) with U-500 insulin was started in conjunction with orally administered mycophenolate mofetil at a dose of $500 \mathrm{mg}$ b.i.d. with the intention of adding intravenously administered rituximab as an outpatient. One day after the first dose of mycophenolate her insulin requirement began 
Table 1 Response to mycophenolate monotherapy

\begin{tabular}{lll}
\hline Test & Pre-therapy & Post-therapy \\
\hline Insulin antibodies & $13 \mathrm{U} / \mathrm{ml}$ & $<0.15 \mathrm{U} / \mathrm{ml}$ \\
GAD-65 antibodies & $1344 / \mathrm{ml}$ & Negative \\
HbAlc & $11.8 \%$ & $6.7 \%$ \\
Weight $/ \mathrm{kg}$ & 72 & 64 \\
Insulin units per day & 400 & 40 \\
Insulin units per $\mathrm{kg}$ & 5.5 & 0.55 \\
\hline
\end{tabular}

to drop, hypoglycemia occurred even with aspart insulin at a basal rate of $0.85 \mathrm{unit} / \mathrm{h}$ and a carbohydrate ratio of 1 unit per $7 \mathrm{~g}$ of carbohydrate. With lowering of basal rates her glucose levels were controlled and she was discharged from hospital. As an outpatient her mycophenolate was increased to $1000 \mathrm{mg}$ b.i.d. which resulted in a further decrease in her insulin requirements. Two months after the original presentation her insulin antibodies were negative, her GAD-65 antibody level had dropped, and her HbA1c was $7.8 \%$ (see Table 1). The planned addition of intravenously administered rituximab, which was delayed for logistical reasons, was found to be unnecessary.

She was continued on mycophenolate $1000 \mathrm{mg}$ b.i.d. for 5 months after the initial presentation. Over the following month she was slowly weaned off mycophenolate without a recurrence of insulin resistance. One year after initial presentation she was still in the "honeymoon period" with her HbA1c being $6.7 \%$ and her total daily utilization of insulin less than 40 units a day $(0.55$ units $/ \mathrm{kg})$ which was $10 \%$ of her initial need (see Table 1 ).

\section{DISCUSSION}

Antibodies to exogenous insulin with the availability of first purified animal insulins and later recombinant DNA human insulin have been greatly but not entirely reduced. However, sporadic occurrences of high insulin antibody titers while being treated with recombinant human insulin or insulin analogues have been reported in both type 1 and type 2 diabetes usually occurring several months or years after the initiation of insulin therapy. Insulin antibodies can lead not only to hypersensitivity but also to glycemic variability, hyperglycemia, ketoacidosis as well as hypoglycemia when the insulin resistance has been overcome and insulin is released from the saturated antibodies.

Therapies that have shown efficacy include withdrawal of insulin and utilization of oral agents in type 2 diabetes. However, with type 1 diabetes replacement of insulin with oral agents is not an option and the proven efficacious treatments are the use of glucocorticoids, plasmapheresis, and immunosuppressants [8-12]. However, there has never been a placebo controlled or randomized study to compare these options and a randomized study is made less likely to occur because of the rarity of this condition.

Glucocorticoid therapy is often counterproductive in that insulin resistance and hyperglycemia are often worsened and the addition of immunosuppressants is needed to either replace or augment glucocorticoid therapy. In addition, in the patient with type 1 diabetes there is a higher risk of ketoacidosis. If these combinations are not successful plasmapheresis is generally recommended. However, plasmapheresis involves hospitalization with its associated expense. Even in the outpatient setting the administration of intravenous immunosuppressants results in considerable expense and inconvenience.

Therefore, an affordable oral immunosuppressant such as mycophenolate (MMF of Cellcept) which has previously been shown to be effective in children should be the preferred initial therapy for EIAS. In this case, after MMF was started, rituximab therapy was prescribed but was delayed for logistical reasons, and oral MMF monotherapy was found to reduce insulin antibody levels so that the resistance to the action of insulin disappeared. The patient has sustained a prolonged remission but continues to have type 1 diabetes which is in excellent control.

In conclusion, for the first time we have shown in adults that exogenous insulin 
antibody syndrome can be treated as an outpatient with mycophenolate monotherapy which potentially avoids the expense of intravenous immunosuppressive therapy and/or plasmapheresis and the expense of hospitalization. Also, earlier treatment of the syndrome prior to the development of hypoglycemia and during propagation of the immune response may allow a quicker remission.

\section{ACKNOWLEDGEMENTS}

Funding. No funding or sponsorship was received for this study or publication of this article.

Authorship. All named authors meet the International Committee of Medical Journal Editors (ICMJE) criteria for authorship for this article, take responsibility for the integrity of the work as a whole, and have given their approval for this version to be published.

Authors' Contributions. Authors contributed equally to the manuscript in all areas.

Disclosures. Terri Jerkins and David S. $\mathrm{H}$. Bell have no disclosures to declare.

Compliance with Ethics Guidelines. Consent to publish was obtained from the patient by Dr Jerkins.

Data Availability. Data is available upon request from Dr. Jerkins.

Open Access. This article is licensed under a Creative Commons Attribution-NonCommercial 4.0 International License, which permits any non-commercial use, sharing, adaptation, distribution and reproduction in any medium or format, as long as you give appropriate credit to the original author(s) and the source, provide a link to the Creative Commons licence, and indicate if changes were made. The images or other third party material in this article are included in the article's Creative Commons licence, unless indicated otherwise in a credit line to the material. If material is not included in the article's Creative Commons licence and your intended use is not permitted by statutory regulation or exceeds the permitted use, you will need to obtain permission directly from the copyright holder. To view a copy of this licence, visit http://creativecommons.org/licenses/by$\mathrm{nc} / 4.0 /$.

\section{REFERENCES}

1. Xiaolei H, Chen F. Exogenous insulin antibody syndrome (EIAS); a clinical syndrome associated with insulin antibodies induced by exogenous insulin in diabetic patients. Endocr Connect. 2018;7:R47-55.

2. Berson SA, Yallow RS, Bauman A, Rothchild MA, Newerly K. Insulin-I131 metabolism in human subjects: demonstration of insulin binding globulin in the circulation of insulin treated subjects. J Clin Investig. 1956;35:170-90.

3. Schernthaner G, Borkenstein M, Fink M, Mayr WR, Menzel J, Schober E. Immunogenicity of human insulin (Novo) or pork monocomponent insulin in HLA-DR-typed insulin dependent diabetic individuals. Diabetes Care. 1983;6(Supplement 1):43-8.

4. Maneshi F, Fineberg SE, Kohner EM. Successful treatment of immune mediated insulin resistance by human insulin (recombinant DNA). Diabetes Care. 1981;5(Supplement 2):175-9.

5. Lahtela JT, Knip M, Paul R, Antonen J, Salmi J. Severe antibody mediated human insulin resistance: successful treatment with the insulin analog lispro. A case report. Diabetes Care. 1997;20:71-3.

6. Yanai H, Adachi H, Hamasaki H. Diabetic ketosis caused by the insulin analog aspart-induced antiinsulin antibody: successful treatment with the newest insulin analog glulisine. Diabetes Care. 2011;34:e108.

7. Malek R, Chong AY, Lupsa BC, et al. Treatment of type B insulin resistance: a novel approach to reduced insulin receptor autoantibodies. J Clin Endocrinol Metab. 2010;9:3641-7.

8. Church D, Cardoso L, Kay R, et al. Assessment and management of anti-insulin autoantibodies in varying presentations of insulin autoimmune syndrome. J Clin Endocrinol Metab. 2018;103(10): 3854-5. 
9. Jassam N, Amin N, Barth JH, et al. Analytical and clinical challenges in a patient with concurrent type 1 diabetes, subcutaneous insulin resistance and insulin autoimmune syndrome. Endocrinol Diabetes Metabol Case Rep. 2014;2014:130086.

10. Segal T, Webb E, Viner R, Pusey C, Wild G, Allgrove J. Severe insulin resistance due to insulin antibodies: successful treatment with the immunosuppressant MMF. Pediatr Diabetes. 2008;9(1):250-4.
11. Ahmed M, Subbalaxmi M, Anne B, Deme S. Recurrent diabetic ketoacidosis and extreme insulin resistance due to anti-insulin antibodies: response to immunosuppression and plasma exchange. Diabetes Technol Ther. 2021;23:227-9.

12. Matsuyoshi A, Shimaoda S, Tsuruzoe K, et al. A case of slowly progressive type 1 diabetes with unstable glycemic control caused by unusual insulin antibody and successfully treated with steroid therapy. Diabetes Res Clin Pract. 2006;72(3): 238-43. 